\title{
Categorías de identidad en el discurso popular urbano del norte de Chile
}

Hans Gundermann K.'

\section{RESUMEN}

En el presente artículo se analiza el discurso producido en un evento de interacción social particular, en el cual se expresan categorías de espacio social, etnia y clase. La contextualización de la situación social en que se emite ese discurso y de las condiciones estructurales y sociohistóricas de su producción, son empleadas para su interpretación como emisión regida por un sistema de categorías sociales vigentes en el discurso popular urbano del norte de Chile.

\section{ABSTRACT \\ In this paper is analized the discourse produced in a particular social interaction event in which categories of ethnic, spacial and clase categories are expressed. The social setting where this event and discourse was emitted as well as your structural and historical context are considered. This conduced to an interpretation in which a system of social categories are explicited. It is concibed as a part of urban popular discourse existent at present in the North of Chile.}

\section{Introducción}

En muy contadas ocasiones le es dado a un investigador asistir como espectador o participar como un actor plenamente involucrado en un contexto

Instituto de Investigaciones Arqueológicas y Museo "R.P. Gustavo Le Paige S.J." San Pedro de Atacama, Universidad Católica del Norte, docente e investigador del Departamento de Ciencias Sociales de la Universidad Arturo Prat, museospa@entelchile.net social en el cual se hacen manifiestas con especial nitidez las relaciones estructurales de un sistema social o se implican las categorías centrales de un campo de significaciones. Esas raras oportunidades representan casos cruciales. Más allá de su carácter placentero o desagradable, su interés radica en las posibilidades ilustrativas y de demostración empírica que el caso tiene para un conjunto de hipótesis o una teoría. Una situación de ese tipo es la que en este artículo se analiza. Atender a ella nos parece apropiado pues consideramos plausible extraer algunas enseñanzas que nos faciliten un mejor entendimiento de las categorías y significados espaciales, étnicos y de clase con los cuales sectores sociales populares del norte de Chile clasifican y organizan conceptualmente la sociedad de la que forman parte. Las páginas siguientes están dirigidas a ese fin.

\section{En las afueras de "La Paila"}

El evento que a continuación relataré ocurrió en Calama, la ciudad minera del norte, una fría mañana de agosto de 1997. Tuvo como protagonistas principales a dos jóvenes obreros ebrios que, saliendo de un bar popular, "La Paila", increparon a los pasajeros que unos pasos más allá esperaban en el borde de la calle la partida del primer bus de línea que a las 8.00 a.m. los trasladaría hasta San Pedro de Atacama.

Para quienes no están familiarizados con Calama recordemos que se trata de una ciudad de mediano tamaño, con algo más de cien mil habitantes, marcada en su historia, fisonomía y funcionamiento por la gran minería del cobre. Constituye, de hecho, una ciudad dormitorio y un centro de servicios, aunque de segundo orden, para la mina 
Chuquicamata. Sirve esas funciones, también, para otras explotaciones mineras de gran envergadura, como Radomiro Tomic y El Abra, las cuales iniciaron faenas durante años pasados. Es una ciudad principalmente de obreros cupríferos. En ella abundan cervecerías generosamente atendidas por diligentes mujeres jóvenes. Bares populares y clandestinos que funcionan hasta la madrugada tampoco escasean. Además de alcohol, el consumo de marihuana o cocaína no es raro durante una noche de juerga. Obreros trasnochadores y dispuestos a la parranda son parte del paisaje nocturno de la ciudad. Dos de ellos son los actores principales de lo que estamos relatando.

Luego de salir del bar, nuestros actores cruzaron la calle y caminaron en dirección a la siguiente esquinat. El estado de intemperancia era manifiesto en la forma de caminar, en sus rostros y la euforia incontinente que los animaba. A mitad de la cuadra se encuentra el paradero de la por entonces única línea de transporte colectivo a San Pedro de Atacama y allí se encontraron con varios pasajeros que esperaban la salida del bus. Se trataba de turistas extranjeros, residentes locales de San Pedro y Toconao y quien relata estos acontecimientos, todos en la acera de la calle y cerca de la puerta de la agencia de pasajes. Al pasar junto a nosotros nos contemplaron desafiantes y nos insultaron varias veces. Nadie reaccionó, temiendo el inicio de un altercado de tono más subido. Casi todos dirigieron sus caras y miradas hacia otro sitio, intentando no dar excusa alguna que indujera a los borrachos seguir con sus exclamaciones e insultos. Quizá debido a esa fingida indiferencia es que continuaron su camino trastabillante. Antes de llegar a la esquina retornaron, luego que un tercer individuo, también salido del clandestino, los llamara a voces. Al pasar nuevamente junto a nosotros las expresiones insultantes se repitieron. Siguieron caminando y se internaron nuevamente en el bar. A los pocos minutos se detuvo un vehículo policial que obligó a salir a los cinco parroquianos rezagados allí presentes, incluidos nuestros héroes. Todos juntos se dirigieron esta vez en el sentido contrario, alejándose de nosotros y profiriendo exclamaciones y riendo a carcajadas.

Digamos que aunque la personalidad de los obreros de la minería está lejos de ser tímida, ninguno en sus sanos cabales tomaría la iniciativa de in- sultar a transeúntes o personas en la calle a menos que alguna razón poderosa los motivara. Por lo demás, quien lo hiciera en esas condiciones arriesgaría una bronca de la que podría no sacar la mejor parte; pero, se tratabal sólo de un par de "curados" descontrolados. Esos dos jóvenes actuaron del modo que lo hicieron bajo evidentes efectos del alcohol, y así lo entendieron quienes tuvieron que sufrirlos.

Habría rápidamente olvidado el incidente de no mediar algunos hechos que me llamaron poderosamente la atención. Uno de ellos es la intensidad y violencia de sus exclamaciones. Fueron insultos fuertes proferidos con gritos destemplados, sin mediar provocación alguna. El segundo, central para mi argumento, es el empleo de etiquetas colectivas bien definidas para dirigirse a los pasajeros. Estas etiquetas presuponen no sólo el reconocimiento de categorías colectivas con las cuales dirigir selectivamente a los miembros de cada una de las clases las respectivas expresiones insultantes; implican también la puesta en operación de una clasificatoria social internalizada. Si a esas clasificaciones sociales agregamos valoraciones y disposiciones a actuar negativas, podríamos disponer de un argumento para explicar la violencia verbal desplegada, además de lo que una noche de "carrete" pudiera generar. Pero lo que me interesa destacar no es en este caso la violencia, sino el empleo de calificativos referidos a origen geográfico, extracción étnica y pertenencia de clase que presuponen la existencia de una sistemática sociológica.

\section{Habitus popular y clasificaciones sociales}

Seguramente no sistematizada y no plenamente consciente en los medios populares, la sistemáticá sociológica de la que hicieron gala el par de obreros existe como conjunto de definiciones asociadas a disposiciones a actuar que se manifiestan y reproducen en las prácticas, en las interacciones sociales cuando allí se dan condiciones que precipitan su emergencia. El habitus ${ }^{2}$ popular parece

Entenderemos por habihus un sistema de disposiciones durables orientadas a la acción, de "estructuras predispuestas a actuar como estructuras estructurantes"; se trata de un sistema subjetivo, no individual, de estructuras interiorizadas que son a la vez csquemas mentales y corporales de percepción. de concep- 
ser rico en distinciones sociológicas en un lugar como Calama y, especialmente, en su vecino meridional, el pueblo de San Pedro de Atacama. Se trata de un territorio de convivencia, coexistencia y contacto frecuente con poblaciones de muy distintos orígenes, pertenencias étnicas, adscripciones nacionales y posiciones de clase. Probablemente, es en torno a esa experiencia de relaciones que se elaboraron los recursos conceptuales y se adquirió la destreza para realizar los reconocimientos y nominaciones que desplegaron los obreros en su incontinente monólogo.

¿Desde dónde socialmente, desde qué capacidades y con qué autoridad hablaron y nominaron, entonces? Ciertamente, se trataba de obreros de extracción popular. Así lo indicaba su vestuario, el uso del castellano y otros detalles de su aspecto y maneras que permiten su identificación. No es posible asegurar que estábamos en presencia de individuos originarios del norte. La gran movilidad de la fuerza de trabajo entre regiones del país es característica del actual modelo económico y el norte y su minería es, ya por más de un siglo, blanco de migraciones desde el centro del país. Uno de ellos, más moreno, tenía la apariencia característica de un obrero nortino en tanto que el otro, quien más insultos profirió, era rubio. Pero, en el mundo popular, aun en el de esta región, la tez blanca, los ojos claros y el pelo rubio no son raros. Como sea, si no eran originarios al menos llevaban algún tiempo en la zona, quizá años, a juzgar por su destreza en reconocer variaciones étnicas, de clase y regionales. En pocos lugares del país es posible familiarizarse con un sistema de clasificaciones que integre simultáneamente todas estas dimensiones; la provincia de El Loa es uno de ellos.

En efecto, el interior de Antofagasta en cuyo corazón se encuentra Calama es a lo menos desde el siglo pasado un espacio de convergencia de poblaciones. Se han hecho presentes una pluralidad de orígenes geográficos y, con ello, distintas nacionalidades (boliviana, chilena, argentina) y diferentes etnías (amerindias como los atacameños del lugar y los quechuas del cercano Potosí y Cochabamba, y europeas como las pequeñas colonias griega, croata, inglesa y estadounidense que allí estuvieron presentes en distintos momentos de este siglo). Sus miembros, además, ocupaban y ocupan también plurales posiciones de clase.

Una cultura sindical y política desarrollada inicialmente en los enclaves salitreros y más tarde en Chuquicamata provee a los mineros del norte y a la población en general percepciones y conciencia de clase bastante desarrolladas. La dinámica social regional no sólo permite que históricamente se elaboren conceptos que rigen visiones y prácticas acerca de las diferencias nacionales y étnicas; seguramente con más fuerza y carga valórica durante su transcurso se elaboraron imágenes y discursos de la diferencia como desigualdad social, de las posiciones y las distinciones de clase.

En agregado de todo lo anterior, digamos que durante la última década se han desarrollado dos fenómenos que movilizan imágenes y experiencias de diferencia social. Por una parte, el auge del turismo en la zona, especialmente hacia San Pedro de Atacama. Por otra, la emergencia de la organización y la acción colectiva reivindicativa indígena. ción y de acción. Tiene un carácter histórico y dinámico; es decir. surge de la exposición repetida a condiciones sociales que imprimen en el cuerpo y la mente de los individuos un conjunto de disposiciones duraderas a la acción. Ya constituido se reproduce de manera abierta, incorporando nuevos esquemas, elemenlos y relaciones de disposición y desechando otros. El habitus es el generador o, más bien, la gramática generativa desde la cual los agentes sociales construyen estrategias conscientes que les permiten enfrentar diversas situaciones. Es por tanto un operador de racionalidad, pero de racionalidad práctica, inmanente al sistema histórico de relaciones sociales. Corresponde a una forma de objetivación de la cultura, del sen- tido y los significados de una sociedad, un grupo social, una comunidad. Es un universal como estructura, pero relativa a las sociedades y las épocas que lo dotaron de sistemas de relaciones particulares. Es un concepto re elaborado por Bourdieu que permite asumir conceptualmente la regularidad y la predictibilidad relativas de la vida social, sin que en cada caso reglas explícitas dirijan la conducta, las disposiciones a actuar, las percepciones y las interpretaciones. Faculta, asimismo, entender su carácter aparentemente teleológico sin tinalidad explícita y su apariencia de orquestación sin un plan colectivamente discĩado. Entre otros textos, consúltese Bourdieu (1988, 1990, 1991, 1993. 1994) y Bourdicu y Wacquant (1992). 
En un caso, se hacen presentes alrededor de 60.000 turistas anualmente muchos de los cuales son europeos y norteamericanos de distintas nacionalidades, además de chilenos del centro del país y de algunos países vecinos (argentinos, sobretodo). San Pedro, el blanco preferente de todo este turismo, es también frecuentemente visitado por residentes de Calama. El pueblo goza de fama como sitio de esparcimiento y "carrete". Los turistas y sus diferencias lingüísticas, físicas y sus modos de conducta y actitudes son muy visibles en San Pedro e incluso en Calama, un sitio de paso hacia el primer pueblo. Por esta vía, por lo tanto, hay numerosas ocasiones para que la población local experimente y construya definiciones y tipificaciones respecto de tales flujos de población. Tales clasificaciones de manera sustantiva remiten a orígenes geográficos, nacionalidades, etnías y posiciones de clase.

En el otro caso, la condición indígena de ciertos segmentos de la población local sufre un vuelco trascendental. En la propia conciencia atacameña y hasta cierto punto también en la de la población criolla regional, tiene lugar durante la última década el paso de una auto-representación étnica estigmatizada ("indio") a una positiva ("atacameño"). ${ }^{3}$ Lo que nos interesa destacar es que estas nuevas nominaciones al estar dotadas de legitimidad y cierto prestigio ${ }^{4}$ desplazan la reproducción social de las clasificaciones y tipificaciones étnicas desde el ámbito de lo privado (donde se vive como vergüenza, como el estigma de "indio") a lo público, donde empieza a pugnar y competir por reconocimiento, valoración, legitimidad interna y, sobretodo, externa. Es en el espacio público de los medios de comunicación de masas locales, privilegiadamente, pero también en reuniones, festivales, manifestaciones públicas (que además alimentan esa presencia en los medios) y la vida cotidiana campesina penetrada por la abrumadora presencia de visitantes donde ahora se procesan las diferencias culturales. A esos espacios tiene acceso potencial toda la población de la zona.

Convengamos, entonces, en que para el común de la población del área que analizamos existen en su vida cotidiana actual posibilidades de experimentar, categorizar y evaluar a individuos y grupos según ejes de estructuración social tan diversos como los presentados. Esa posibilidad existió también en el pasado, debido a lo cual nos encontramos, presumiblemente, con un esquema de categorías construido alrededor de la experiencia histórica de convergencia arriba resumida. Aquel es enriquecido por nuevos fenómenos de migración, movilidad y flujo de poblaciones muy heterogéneas que, además, resaltan su distintitividad a tenor de las sensibilidades sobre la pluralidad cultural que hoy gozan de crédito. ${ }^{5}$

\section{Identidades colectivas en el discurso popular}

Si la realidad de las identidades se constituye, parcialmente al menos, por la condición performativa de las nominaciones sociales que las designan y contribuyen a otorgarles existencia, Ia endo y exo denominaciones y definiciones que se construyen en las prácticas sociales confieren, para los actores implicados, realidad a los sujetos colectivos que nombran y califican. ${ }^{6}$ De esta manera, los protagonistas principales de esta historia, si hemos de juzgar a partir de sus expresiones, asumían estar efectivamente en presencia de individuos representantes de a lo menos tres grandes categorías sociales: "indio", "gringo" y "santiaguino". En algún momento se expresaron de sí mismos, además, como "pueblo".

Según lo anterior, en el evento analizado salieron a relucir cuatro macro entidades sociales, constituyentes de lo que podríamos llamar un subsistema

3 Un neologismo prestado desde la etnología. ya que con el localismo "atacameño" se designaba en la zona sólo a los habitantes o personas oriundas de San Pedro de Atacama. Constituía un gentilicio de localidad, no de etnía, por lo tanto.

4 Dados por las ideologías indianistas de una elite de dirigentes indígenas, pero también alimentados por sensibilidades neo románticas y culturales de los cuales son portadores privilegiados no solo antropólogos, sino también ciertos segmentos de población de paso por la zona.

5 No consideramos aquí género, generaciones y "tribalidades" modernas, por no estar directamente implicados en el evento que nos sirve de guía para el análisis.

6 El punto merece una aclaración. Bourdieu dirá que "la logique spécifique du monde social, cette "réalité" qui est le lieu d'une lutte permanente pour définir la "realité"" (1980:67). Otra manera de expresar lo an- 
de categorías sociales. Es de importancia analizar las adjetivaciones y valoraciones que salieron a relucir y, luego, las relaciones entre los elementos de este subsistema, de tal manera de alcanzar una interpretación y perspectiva de conjunto del suceso. Hasta donde puedo percibir de las notas tomadas, en la lógica del discurso empleado se utilizaron conexiones de sentido diádicas, por lo que es pertinente un análisis de relaciones término a término o mediante dicotomías.

El término "indio" fue adosado a algunos de los pasajeros que esperaban en la acera; en particular a aquellos de tez morena y rasgos (faciales, vestuario, posición del cuerpo, tipo de equipaje y bultos, entre otros) atribuibles a una condición indígena. Las valoraciones manifestadas parecen ser ambiguas y, en cualquier caso, expresivas de distancia social. ${ }^{7}$ Por una parte, profirieron insultos hacia ellos del tipo como: "indio culiaoh"; por otro, hablaron de San Pedro de Atacama, de donde son oriundos y residen esos "indios", como un lugar "místico". Pero esto último no se vería como algo negativo, más bien al contrario, en tanto es un lugar reputado como idóneo para experiencias místicas (religiosas o naturalistas, con o sin psicotrópicos, etc.). Se asume que San Pedro y sus inmediaciones, ese espacio en particular, posee propiedades místicas remarcables. Aunque lo místico suelen ser caracterizado como una propiedad de las prácticas de los indígenas, no parece en este

terior en relación con las identidades es postulando que la realidad de una identidad corresponde en gran medida con la realidad de su representación y de su reconocimiento. En la medida que la representación de la identidad cuente con condiciones para imponerse como representación legítima y autorizada, validación que obtiene como resultado de la correlación de fuerzas simbólicas y las condiciones materiales que las sustentan, entonces podrá cumplir con éxito una función performativa (conferir realidad y efectividad a lo representado). Sólo de esta manera puede superarse una concepción ingenua de la relación entre representación y realidad. Por lo tanto, las identidades son, en parte al menos, el efecto de representaciones que en el pasado lograron reconocimiento social en el curso de luchas simbólicas por la identidad. Existen hoy como identidades establecidas o estatuidas que operan como estructuras objetivas socialmente cristalizadas y son el objeto, al mismo tiempo, de es- caso estar procediéndose a asimilar simplemente el espacio "místico" con sus usuarios tradicionales. La identificación existe, pero es parcial, debido a que las experiencias místicas son demandadas por un público mucho más amplio que el de los indígenas. Se diluye de este modo un nexo objetivo entre espacio místico y cultura indígena: una de las fuentes objetivas de la atribución de propiedades místicas a ese espacio es, precisamente, la de los discursos religiosos y las prácticas rituales atacameñas. ${ }^{8}$ Así las cosas, se procede a construir un hiato entre una valoración negativa de un grupo social y una visión positiva de su habitat histórico. De todos modos, lo místico fue en ese momento y contexto particular planteado como algo exterior, ajeno a sí mismos, ya que en el par de ocasiones en que se lo manifestó las exclamaciones tuvieron un tono afirmativo, pero dirigido a los "gringos" y "santiaguinos" como información e inducción a consumo y en ningún caso como algo propio o deseo propio exteriorizado.

Los atuendos, mochilas de viaje que portaban y algunos de sus atributos físicos denunciaron a los "gringos", una categoría que en nuestro país designa tanto a los norteamericanos como a los europeos. Es un concepto que fija su ámbito de aplicación sobre tipos físicos anglosajones y de Europa del norte, si es que algo así tuviera una existencia objetiva distinguible con claridad. En los medios populares se trata en realidad de una denomi-

fuerzos por reproducirlas, de modificarlas, de explotarlas en beneficio de determinados agentes sociales. de reemplazarlas por nuevas formas de identidad, de esfuerzos de resistencia. etc.

7 En este contexto, entenderemos por distancia social los tipos de relaciones sociales que un individuo o un grupo está dispuesto, en diferentes grados, a entablar con otros individuos u otros grupos y los límites hasta los cuales esta disposición se encuentra presente. Por ejemplo, intercambios lingüísticos, colaboración laboral, relaciones sexuales, alianzas matrimoniales, etc.

8 Agradezco a Daniela Serra llamarme la atención acerca de la convergencia en San Pedro de Atacama de varias sensibilidades culturales que incorporan sus propias versiones (discursos y prácticas) de lo místi$\mathrm{co}$, las cuales coexisten, se superponen o entran en conflicto con prácticas comparables atacameñas. 
nación que intenta aprehender una constelación más o menos difusa de rasgos físicos, con fronteras poco claras, atribuibles a extranjeros de esos orígenes. De hecho, nacionales pueden ser confundidos fácilmente como "gringos", como en ese momento me ocurrió, e individuos provenientes de esas regiones pueden fácilmente no ser clasificados de ese modo (afroamericanos o personas del sur de Europa, por ejemplo). Como en el caso anterior, el concepto se asocia a valores ambiguos: por una parte, quienes son etiquetados como tales representan el poder económico, el desarrollo tecnológico, la modernidad en sus diversas manifestaciones que sus sociedades y estados poseen; por otra, son también miembros de sociedades cuyas clases dominantes y centros de poder han históricamente explotado y establecido relaciones asimétricas con diversas periferias. En la memoria de todos los nortinos está presente alguna versión del dominio norteamericano sobre el cobre chileno $y$, en particular de su control del centro cuprífero de Chuquicamata por alrededor de medio siglo. Quizá por ese tipo de representaciones es que, sin aviso, nuestros actores les endosaron con el mayor desparpajo un sonoro "fucking you."

La condición de "santiaguino" la recibí después que, siendo tratado de "gringo", les pedí en castellano que siguieran su camino. Es en ese momento que la distinción entre "pueblo" o popular y "santiaguino" se hizo palpable. Tal parece que con este concepto denotaron la idea de capitalino de clase media acomodada o metropolitano de altos ingresos. Con ese origen llegan numerosos visitantes a la zona, pero ciertamente sólo una fracción de ellos caen bajo esa condición socio económica; por lo general a "mochileros" u obreros de la capital no se les llama "santiaguinos." En el contexto de interacción que comentamos ciertamente se estaba usando una acepción restringida de "santiaguino." Denotaba una extracción geográfica $y$, dentro ella, una posición de clase bien determinada, claramente diferenciada de "pueblo", de lo popular.

Si en un sentido las identidades existen en y por el reconocimiento dado por los otros, entonces, desde una autoafirmación de "pueblo", de clases populares $y$, subalternas, como luego veremos, los conceptos de "indio", "gringo" y "santiaguino" imputados a un grupo de personas constituyen, por efecto de ese discurso, identidades sociales, colectividades consignadas por esas nominaciones y atributos. Tales propiedades representan desde la posición del emisor, en esa particular situación y contexto, núcleos de sentido fuertes que prevalecen sobre otras posibles imputaciones y que por lo tanto definen y dividen las identidades del universo social al que se remiten. Su conjunto conforma una clasificatoria social, categorías sociológicas relacionadas y, por eso mismo, un sistema de identidades.

El subsistema de categorías que analizamos constituye un campo semántico, un conjunto de expresiones significantes vinculadas por haces de significación. Si esto es así, ¿qué asociaciones y de qué tipo podemos aislar entre los conceptos que describiéramos en uso en esas circunstancias?; y, realizado lo anterior, ¿qué podemos aprender de las representaciones populares acerca de raza, etnía, localidad y clase extrovertidas en un acceso de euforia y agresividad alcohólica?

Las trazas de asimilaciones categoriales y de separación o distancia social expresadas a través del discurso pueden permitirnos algunos avances en el análisis. La primera y más obvia asimilación es la que se da entre "gringo" y "santiaguino": si no era "gringo" como se supuso inicialmente, se me asimiló inmediatamente a una subclase de santiaguino (a través de señales de reconocimiento como la forma dialectal del castellano empleada, el aspecto físico, el atuendo, etc., expresivas de ciertas posiciones generales de clase). En este sentido es que "santiaguino" puede ser considerado análogo de "gringo". ¿Qué comparten en común en el imaginario popular? Posiblemente, un capital educacional alto, profesionalización, cierto cosmopolitismo, capacidad de viajar y, en la situación local, un común interés de consumo "místico" y de paisajes. En definitiva, estilos y proyectos de vida relativamente semejantes. Esto los hace en aspectos sustanciales posicionables bajo una misma condición de identidad. La comunión de "gringo", "santiaguino" e "indio" en torno a lo místico es una intersección parcial y acotada al terreno del consumo turístico, efímero por definición. No podemos en tal caso tomarla como una asimilación estructural, una identidad.

Las dicotomías, en cambio, son mucho más evi- 
dentes. La posición desde la que se sitúan los actores centrales del evento es la de "pueblo", como lo hicieron expresamente manifiesto. Desde este sitial se diferencian y toman distancia de los individuos que asumen como miembros de determinadas identidades. Lo hacen desde varios ejes de significación. Uno de ellos es el de clase. Se emiten expresiones insultantes a otros desde una identidad de clase propia que es la de "pueblo" hacia posiciones de clase de ingresos medios y altos. Insultar es un acto de fuerza, violento, afortunadamente sólo de naturaleza lingüística en el evento que analizamos, destinado a ofender, humillar, denostar, rebajar, etc. En el contexto en que se produjeron, tales actos representan, según creemos, una modalidad acentuada de manifestar distancia, de hacer sentir con fuerza el rechazo, y algo más. Si la subjetividad de clase posiciona a "pueblo" como clase dominada, se agravia, en esa medida, desde una ubicación subalterna en las jerarquías objetivas de clase, pero poniendo coyunturalmente entre paréntesis esa posición de inferioridad a través del desafío y la provocación. Se trata, a fin de cuentas, de actos de rebeldía y libertad.

Hacia el "indio" no se manifiesta distancia de clase; posiblemente a este nivel se establezca una asimilación general como categorías sociales subordinadas. Una diferencia y distancia marcada con fuerza se expresa, en cambio, a través de un eje cultural. Los "indios" están del lado de lo "místico" y por esta vía de la tradición; ésta, en tanto, se asocia a conservación, a continuidad cultural, en oposición a modernidad y civilización, una dupla conceptual que en estas regiones alimenta desde los sectores populares una larga historia de estereotipos y prejuicios acerca de los indígenas. El desprecio hacia el indio no constituye un acto emancipatorio; por el contrario, expresa la incapacidad de aceptar las diferencias culturales. Por esta vía, expresa la negación de las personas que detentan, real o imaginariamente, ${ }^{9}$ una cultura diferente. A pesar de la relativa igualdad social estructural de "indios" y "pueblo", una considerable distancia los separa en cuanto al bajo prestigio que los del "pueblo" reconocen a los "indios". Tal rechazo despreciativo es expresivo de desniveles fundados en un bajo reconocimiento y legitimidad otorgado al otro. Lo que se cometió en ese lugar fueron, a no dudarlo, actos de intoleran- cia.

La diferencia cultural también fue manifiesta hacia "gringo", como categoría de población cuyos miembros se comunican en otra $u$ otras lenguas y que detentan otros estilos de vida, siguen otras trayectorias vitales, optan por patrones de consumo particulares, forman parte de sociedades diferentes, están más próximos al poder y la modernidad plena, etc. La asimilación con "santiaguino" puede prolongarse también a la esfera cultural. En este último caso son diferencias culturales asociadas a clase social y no a una diferente etnía y nacionalidad, las cuales son evaluadas como convergentes con la cultura de los países de origen de los visitantes extranjeros. El desprecio étnico se identifica, en este último caso, con distancia de clase.

Por otra parte, la Atacama mística se representa como rural; se opone a "pueblo", en tanto este concepto es en nuestro país prácticamente sinónimo de ciudad y urbano. Ella misma se opone, sobre el eje de los espacios sociales, de "gringo" y "santiaguino", ambos con connotaciones urbanas, si es que no metropolitanas. Desde este punto de vista, el de un eje espacial, en el discurso analizado Atacama de "indio" se opone a "pueblo", "santiaguino" y "gringo" en tanto el uno es rural y los otros urbanos. Pero desde "pueblo" el valor de lo rural es contradictorio (de una parte se denotan imágenes bucólicas, pero de otra, quizá con más fuerza, es expresivo de incomodidad, aislamiento, restricciones de acceso a servicios, rusticidad, etc). Al insultar a "indios" rurales, sin duda se está destacando esta segunda vertiente de sentido. El rechazo étnico tiene entonces como complemento una visión a lo menos controversial de lo rural. Esta versión contradictoria del mundo rural nortino

La distancia cultural objetiva entre obreros "chilenos" y "atacameños" es poca. Repárese en el hecho que ambos grupos comparten desde hace muchas décadas similares espacios laborales y residenciales, así como áreas comunes en sus respectivos estilos de vida y consumo. Por lo demás, la transitividad étnica ha sido durante este siglo bastante activa (actualmente. se daría en los dos sentidos, a tenor de las ventajas provistas por políticas de acción afirmativa que favorecen autoadcripciones a veces arbitrarias de "atacameño"). En este caso, los marcadores étnicos corresponden con unos pocos atributos selectivos que destacan una diferencia ante todo simbólica. 
no estaría presente en las otras categorías sociales implicadas, para quienes el consumo de los paisajes que visitan tiene un alto valor.

\section{Conclusiones}

Jerarquías de clase social, diferencias étnicas y diferencias de espacio social son los ejes de significación a través de cuyas variaciones se conforma el sistema de representaciones contenidos en el discurso de dos personas. Las relaciones de igualdad (asimilación) y diferencia (oposición) que unen los sujetos aludidos manifiestan una visión sistémica de la sociedad en el imaginario de individuos que se autoperciben formando parte de los sectores populares de una ciudad minera del norte del país. En un acto a fin de cuentas intrascendente, espontáneo y realizado en condiciones de desbloqueo de la vigilancia acerca de los códigos apropiados para el apropiado posicionamiento social que lleva implicada toda interacción, dos individuos desaforados por el alcohol hicieron expresión de su animosidad y distancia de clase, étnica y regional con individuos a quienes atribuyeron las identidades analizadas.

Su valor empírico es ese: el que sin mayor contención se expresara su grosero desprecio por los otros y en que en este manifestar acarrearan y trajeran al tapete categorías sociales y determinadas significaciones asociadas a ellas, expresivas de una visión popular de la conformación y estructura de la sociedad. Su valor metodológico es el de proporcionar una evidencia condensada que hace posible explorar un campo de significaciones cuyos elementos y relaciones de otro modo deberían reconstruirse penosamente. Su valor teórico lo afirmo en el valor de un análisis de las identidades colectivas que recupere a actores social e históricamente situados que despliegan una subjetividad, la cual debe tanto a la coyuntura y circunstancias de las interacciones sociales en que participan, como a las disposiciones a ver y actuar regidas por la cultura del grupo de pertenencia que se actualizan en esas relaciones.

\section{BIBLIOGRAFÍA}

\begin{abstract}
BOURDIEU, $P$. "L'identité et la représentation. Eléments 1980 pour une réflexion critique sur l'idée de région" en Actes de la Recherche en Sciences Sociales, $\mathrm{N}^{\circ} 35, \mathrm{pp} .63-72, \mathrm{~Pa}-$ rís, Francia.
\end{abstract}

1988 La distinción. Criterios y bases sociales del gusto. Ediciones Taurus, Madrid. España (de la versión francesa de Les Editions du Minuit, 1979)

1990 Sociología y cultura. GrijalboConaculta, México (de la cdición francesa de 1984)

1991 El sentido práctico. Taurus Ediciones, Madrid. España. paña (de la edición francesa de Les Editions du Minuit, 1987)

1999 ¿Qué significa hablar?, Akal, España (Ira. edición francesa de 1985)

BOURDIEU, P. y L. WACQUANT, Réponses. Pour une 1994 anthropologie reflexive. Editions du Seuil, France.

GONZÁLEZ, H. "Apuntes sobre el tema de la identidad 1998 cultural en la región de Tarapacá" en Estudios Atacameños $N^{\circ} 13$, pp. 27-45

GUNDERMANN, H. "Identidades colectivas y resistencia 1999 étno-local a megaproyectos de inversión". El caso del By pass de San Pedro de Atacama", Ms. 